\title{
Prostate-specific antigen nadir concentration, hypertension and diabetes as risk factors for biochemical failure after permanent ${ }^{125}$ I seed brachytherapy for prostate cancer
}

\author{
ESSI KOVALAINEN and MARKKU H. VAARALA \\ Department of Operative Care, Division of Urology, Medical Research Center Oulu, \\ Oulu University Hospital, University of Oulu, 90220 Oulu, Finland \\ Received July 1, 2016 ; Accepted August 18, 2016
}

DOI: $10.3892 / \mathrm{mco} .2016 .1014$

\begin{abstract}
The aim of this study was to evaluate risk factors for biochemical failure (BF) following permanent prostate seed ${ }^{125}$ I brachytherapy for prostate cancer. The study reviewed the medical records of 607 patients with biopsy-proven prostate adenocarcinoma who were treated at Oulu University Hospital between 2001 and 2014. Clinical characteristics at diagnosis, treatment-related data and follow-up data were collected to identify potential risk factors for BF, which was defined using the Phoenix criteria [prostate-specific antigen (PSA) increase $>2 \mu \mathrm{g} / \mathrm{l}$ from the PSA nadir concentration, which defined as the lowest PSA concentration observed after BT]. The median follow-up was 81 months. BF was detected in 117 (19.3\%) patients. The PSA nadir concentration was associated with BF. The mean times to BF were 114 [95\% confidence interval (CI): 112-116] and 55 (95\% CI: 47-63) months for patients with PSA nadir concentrations $<0.5$ and $\geq 0.5 \mu \mathrm{g} / 1$, respectively $(\mathrm{P}<0.001)$. Patients with underlying hypertension or diabetes tended to develop BF more rapidly. For patients without and with hypertension, the mean times to BF were $104(95 \%$ CI: 100-107) and 98 (95\% CI: 93-103) months, respectively $(\mathrm{P}=0.035)$. For patients without and with diabetes, the mean times to BF were 103 (95\% CI: 100-106) and 89 (95\% CI: 77-102) months, respectively $(\mathrm{P}=0.006)$. The overall survival and prostate cancer-specific survival rates were 90.3 and $98.0 \%$, respectively. The mean overall survival and prostate-cancer specific survival times were 147 and 158 months, respectively. Therefore, PSA nadir level was identified as a clear risk factor for BF. In addition, BF tended to develop more rapidly among patients with underlying hypertension or diabetes. These
\end{abstract}

Correspondence to: Dr Markku H. Vaarala, Department of Operative Care, Division of Urology, Medical Research Center Oulu, Oulu University Hospital, Kajaanintie 50, PO Box 21, 90029 Oulou, Finland

E-mail: markku.vaarala@oulu.fi

Key words: prostate cancer, brachytherapy, treatment, retrospective chart review risk factors should be considered, and individually tailored follow-up may be useful for identifying patients requiring more intense follow-up for early BF detection.

\section{Introduction}

In 2012, prostate cancer was the most common cancer among European men, comprising $12 \%$ of all new cancer cases and $5 \%$ of all cancer deaths. This incidence was the highest in high-income countries (1). Treatment of localized disease varies, as there is no evidence that one treatment is more effective compared with another (2). According to the current guidelines of the American Urological Association (3) and the European Urological Association (4), the treatment of low-risk, localized prostate cancer may include active surveillance, prostatectomy, or either interstitial or external-beam radiation therapy. Permanent seed brachytherapy (BT) is mostly used for patients with low prostate-specific antigen (PSA) concentrations and low Gleason scores. For these patients, studies have shown no significant difference in clinical effectiveness among treatments (5). According to previous studies, the 5-year disease-free survival is $\sim 80-90 \%(5,6)$.

The aim of this study was to evaluate risk factors for biochemical failure (BF) after permanent seed ${ }^{125} \mathrm{I}$ BT for prostate cancer among patients treated in Oulu University Hospital. The study consisted of a retrospective chart review conducted to evaluate clinical characteristics at diagnosis, treatment-related details and follow-up data.

\section{Materials and methods}

Chart review. Between March, 2001 and December, 2014, 607 patients received treatment for early-stage (T1/2N0M0), histologically confirmed prostate cancer using ${ }^{125} \mathrm{I}$ seed BT. Study data were collected retrospectively from their medical records at Oulu University Hospital (Oulou, Finland) and at other hospitals for those who were followed up elsewhere, including local hospitals in Kajaani, Kemi, Kokkola, Oulainen and Rovaniemi. The following data were recorded: Patient age, former diagnosis, Gleason score, TNM stage, PSA concentration prior to treatment, PSA nadir concentration, possible 
increase in PSA concentration during follow-up, all additional treatments for prostate cancer before or after BT, and possible radiological progression. Treatment outcome was defined in terms of time to PSA nadir concentration, BF, defined as PSA concentration progression $>2 \mu \mathrm{g} / 1$ from the PSA nadir concentration according to the Phoenix criteria (7), treatment of BF, and overall and prostate-cancer specific survival. PSA nadir concentration was defined as the lowest PSA concentration observed after BT. After treatment, the patients were followed up at 3,6 and 12 months, then biannually for 4 years, and annually thereafter. More frequent follow-ups were possible based on the decisions of the urologists/doctors responsible for the follow-ups. There were no strict treatment protocols following BF.

Ethics. According to Finnish legislation and directions from Finnish Ethics Committees, this chart review was exempted from formal approval by the Institutional Review Board. However, the study was conducted according to the principles of the Helsinki Declaration.

BT technique. The dose plan was based on ultrasonic (US) images taken at $0.5-\mathrm{cm}$ intervals and used stranded seeds $\left({ }^{125} \mathrm{I}\right.$ IsoCord $^{\circledR}$; Bebig GmbH, Berlin, Germany). The implantation technique was intraoperative and used sagittal images. VariSeed 8.0 (Varian; Palo Alto, CA, USA) was used for dose planning and for calculating the dose-volume histogram. The actual dose plan was performed using ${ }^{125}$ I IsoCord S06 seeds (Bebig $\mathrm{GmbH}$ ). The prescribed dose was $145 \mathrm{~Gy}$ using seed activity of $17.46 \mathrm{MBq}(0.472 \mathrm{mCi})$.

Statistical analysis. Unless otherwise stated, the summary statistics included the mean, range and standard deviation (SD) or, if biased, the median with the 25-75th percentile. Survival analyses and analyses of time to BF were conducted using the Kaplan-Meier method, and the statistical significance of the differences between groups was analysed using the log-rank test. The data were analyzed using SPSS statistical software, version 22.0 (IBM SPSS; Armonk, NY, USA). Two-tailed P-values are reported, and P-values $<0.05$ were considered to indicate statistically significant differences.

\section{Results}

Patient characteristics. Follow-up details were available for 605 patients, and survival data were available for 606 patients. The mean age at BT was 64 years (range, 44-78; SD, 6.1). The median PSA concentration prior to BT was 7.7 (25-75th percentiles, 5.5-10.0). The median prostate volume was $29.0 \mathrm{~cm}^{3}$ (25-75th percentiles, 23.3-35.9). The median number of seeds used was 55 (25-75th percentiles, 47-63). The median number of needles used was 21 (25-75th percentiles, 19-23). Of the 607 patients, $537(88.5 \%), 69(11.4 \%)$ and $1(0.2 \%)$ had Gleason scores of 6,7 and 8, respectively, on prostate biopsy. The clinical T-stage according to the TNM classification (8) was cT1 and cT2 in 400 (65.9\%) and 207 (34.1\%) patients, respectively. Prior to BT, 91 patients $(15 \%)$ received neoadjuvant hormonal therapy with the intention of decreasing the prostate volume to $<50 \mathrm{~cm}^{3}$. The median duration of this

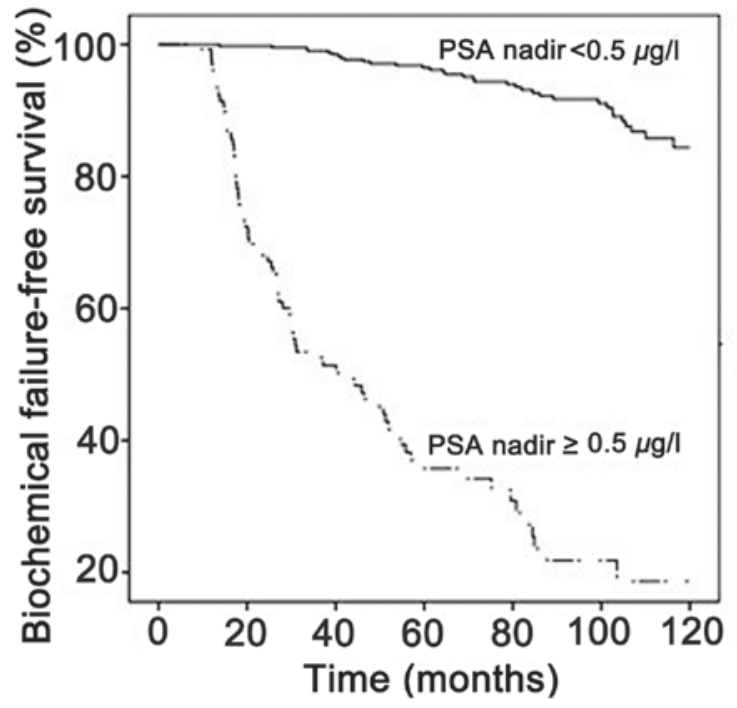

Figure 1. Association of PSA nadir value after permanent seed BT with BF-free survival among prostate cancer patients. BF was common among patients with PSA nadir concentrations $\geq 0.5 \mu \mathrm{g} / 1$ after BT $(\mathrm{P}<0.001)$. PSA, prostate-specific antigen; BT, brachytherapy; BF, biochemical failure.

neoadjuvant hormonal therapy was 5 months (25-75th percentiles, 3-9).

The median follow-up time was 81 months (range, 2-161; $\mathrm{SD}, 39$ ). After a mean of 46 months (range, 8-136; SD , 32), 117 (19.3\%) patients developed BF and $91(15.0 \%)$ were treated for BF. For those patients, the mean time to the first treatment after BT was 57 months (range, 12-149; SD, 34). The first treatment selected was antiandrogens $(n=47,51.6 \%)$, chemical castration $(\mathrm{n}=29,31.9 \%)$, external-beam radiation therapy $(\mathrm{n}=11,12.1 \%)$ or radical prostatectomy $(\mathrm{n}=2,2.2 \%)$. In addition, as an initial treatment for BF, 2 patients $(2.2 \%)$ were treated with a $5-\alpha$ reductase inhibitor. During follow-up, 32 (5.3\%) patients received external-beam radiation therapy. Eventually, 21 (3.5\%) developed metastatic disease, the mean time to which was 66 months (range, 18-149; SD, 43). Of the 606 patients. 12 succumbed to prostate cancer and 47 to other causes. The overall survival and prostate-cancer specific survival rates were 90.3 and $98.0 \%$, respectively. The mean overall survival time and prostate-cancer specific survival time were 147 and 158 months, respectively.

$\mathrm{BF}$ was significantly more common among patients with PSA nadirs $\geq 0.5 \mu \mathrm{g} / 1$ compared with those with PSA nadirs $<0.5 \mu \mathrm{g} / 1$ (Fig. 1). The mean time to BF was 55 [95\% confidence interval (CI): 47-63] and 114 (95\% CI: 112-116) months for patients with PSA nadirs $\geq 0.5 \mu \mathrm{g} / 1$ and $<0.5 \mu \mathrm{g} / 1$, respectively $(\mathrm{P}<0.001)$.

We further evaluated the potential association of underlying diseases with BF. BF tended to develop more rapidly among patients with hypertension or diabetes at diagnosis. For patients without and with hypertension, the mean time to BF was 104 (95\% CI: 100-107) and 98 (95\% CI: 93-103) months, respectively $(\mathrm{P}=0.035)$. For patients without and with diabetes, the mean time to BF was 103 (95\% CI: 100-106) and 89 (95\% CI: 77-102) months, respectively ( $\mathrm{P}=0.006)$. Other comorbidities, including coronary artery disease, previous myocardial infarctions, other cancers, or obstructive pulmonary disease, did not affect the time to BF. Due 
to the small number of deaths, further survival analyses for overall survival and prostate-cancer specific survival were not performed.

\section{Discussion}

BT is an option for treating low-risk prostate cancer, and it has achieved promising results in terms of disease recurrence (9-18); however, certain patients still develop disease recurrence. In search of the risk factors for BF after BT, PSA nadir was identified as a strong predictor of BF. For patients with PSA nadirs $\geq 0.5 \mu \mathrm{g} / 1$, the mean time to BF was $<6$ years, whereas it was $>9$ years for patients with PSA nadirs $<0.5 \mu \mathrm{g} / 1$. Recently, McLaren et al (19) published their institutional results, reporting that PSA concentrations of $>0.4 \mu \mathrm{g} / 1$ over the PSA nadir predict disease recurrence. In addition, their analyses demonstrated that, if their PSA nadir was $>0.8 \mu \mathrm{g} / 1$ (19), approximately half of the patients experienced disease relapse within 4 years, a finding that is in line with the results of the present study.

Comorbidities, including hypertension and diabetes, have previously been associated with decreased overall survival following BT $(20,21)$. Despite the promising results of lower mortality among prostate cancer patients exposed to metformin (22), an analysis of 270 men with diabetes, with and without metformin use, revealed no association between metformin use and progression-free, disease-free, or overall survival following treatment with BT (23). Similar results were found in another cohort of 199 diabetes patients, in which diabetes did not affect cancer-specific survival or biochemical progression following BT (24). However, increased blood glucose levels have been associated with increased risk of disease recurrence following radical prostatectomy or radiation therapy as a radical treatment for prostate cancer (25). The finding of the present study regarding a tendency toward more rapid $\mathrm{BF}$ among patients with underlying diabetes or hypertension is partly supported by previously published results in cases with diabetes (25). To the best of our knowledge, hypertension has not been associated with progression-free survival in prostate cancer. However, the findings of the present study require evaluation in other cohorts. In addition, the presence of a clinically meaningful association with BF remains obscure, as the mean time to BF was long (89-104 months).

Our study was limited by its retrospective, single-center nature. In addition, the study did not evaluate diabetes medications or the use of statins, although they may have a positive prognostic effect (26). Furthermore, the small number of deaths did not enable reliable survival analyses. Moreover, BF was defined according to the Phoenix criteria, which have been shown to be more sensitive and specific in defining BF in patients treated with BT. However, it has been demonstrated that the ASTRO and Phoenix criteria (7) have a $~ 8 \%$ difference in the rate of biochemical control, with the latter achieving lower values (27). Finally, comparing among various studies is difficult due to the differing definitions used.

However, the results of the present study indicate that low PSA nadir reliably predicts BF after BT. Patients with underlying hypertension or diabetes tended to exhibit shorter times to $\mathrm{BF}$, emphasizing the need for more attentive follow-up of such patients after BT. However, these findings require further investigation.

\section{Acknowledgements}

We are grateful to Leena Heikkilä for assisting with data collection, and to Pasi Ohtonen, MSc, for assisting with statistical analyses.

\section{References}

1. Prostate (PRC) cancer factsheet. http://www.encr.eu/images/ docs/factsheets/ENCR_Factsheet_Prostate_2014.pdf. Accessed 04/17, 2016

2. Wilt TJ, MacDonald R, Rutks I, Shamliyan TA, Taylor BC and Kane RL: Systematic review: Comparative effectiveness and harms of treatments for clinically localized prostate cancer. Ann Intern Med 148: 435-448, 2008.

3. Guideline for the management of clinically localized prostate cancer (2007). https://www.auanet.org/education/guidelines/ prostate-cancer.cfm. Updated 2007. Accessed 04/17, 2016.

4. Heidenreich A, Bastian PJ, Bellmunt J, Bolla M, Joniau S, van der Kwast T, Mason M, Matveev V, Wiegel T, Zattoni F, et al: EAU guidelines on prostate cancer. Part II: treatment of advanced, relapsing and castration-resistant prostate cancer. Eur Urol 65: 467-479, 2014.

5. Norderhaug I, Dahl O, Høisaeter PA, Heikkilä R, Klepp O, Olsen DR, Kristiansen IS, Waehre $H$ and Bjerklund Johansen TE: Brachytherapy for prostate cancer: A systematic review of clinical and cost effectiveness. Eur Urol 44: 40-46, 2003.

6. Zelefsky MJ, Hollister T, Raben A, Matthews S and Wallner KE: Five-year biochemical outcome and toxicity with transperineal CT-planned permanent I-125 prostate implantation for patients with localized prostate cancer. Int J Radiat Oncol Biol Phys 47: 1261-1266, 2000

7. Roach M III, Hanks G, Thames H Jr, Schellhammer P, Shipley WU, Sokol GH and Sandler H: Defining biochemical failure following radiotherapy with or without hormonal therapy in men with clinically localized prostate cancer: Recommendations of the RTOG-ASTRO Phoenix Consensus Conference. Int J Radiat Oncol Biol Phys 65: 965-974, 2006.

8. Sobin L and Wittekind C: Union for international cancer control: TNM classification of malignant tumours. 6th edition. Wiley, New York, 2002.

9. Grimm PD, Blasko JC, Sylvester JE, Meier RM and Cavanagh W: 10-year biochemical (prostate-specific antigen) control of prostate cancer with (125)I brachytherapy. Int J Radiat Oncol Biol Phys 51: 31-40, 2001.

10. Zelefsky MJ, Kuban DA, Levy LB, Potters L, Beyer DC, Blasko JC, Moran BJ, Ciezki JP, Zietman AL, Pisansky TM, et al: Multi-institutional analysis of long-term outcome for stages T1-T2 prostate cancer treated with permanent seed implantation. Int J Radiat Oncol Biol Phys 67: 327-333, 2007.

11. Potters L, Morgenstern C, Calugaru E, Fearn P, Jassal A, Presser J and Mullen E: 12-year outcomes following permanent prostate brachytherapy in patients with clinically localized prostate cancer. J Urol 179 (5 Suppl): S20-S24, 2008.

12. Aaltomaa SH, Kataja VV, Lahtinen T, Palmgren JE and Forsell T: Eight years experience of local prostate cancer treatment with permanent 1125 seed brachytherapy-morbidity and outcome results. Radiother Oncol 91: 213-216, 2009.

13. Hinnen KA, Battermann JJ, van Roermund JG, Moerland MA, Jürgenliemk-Schulz IM, Frank SJ and van Vulpen M: Long-term biochemical and survival outcome of 921 patients treated with I-125 permanent prostate brachytherapy. Int J Radiat Oncol Biol Phys 76: 1433-1438, 2010.

14. Henry AM, Al-Qaisieh B, Gould K, Bownes P, Smith J, Carey B, Bottomley D and Ash D: Outcomes following iodine-125 monotherapy for localized prostate cancer: The results of leeds 10 -year single-center brachytherapy experience. Int J Radiat Oncol Biol Phys 76: 50-56, 2010.

15. Crook J, Borg J, Evans A, Toi A, Saibishkumar EP, Fung S and Ma C: 10-year experience with I-125 prostate brachytherapy at the Princess Margaret Hospital: Results for 1,100 patients. Int J Radiat Oncol Biol Phys 80: 1323-1329, 2011. 
16. Marshall RA, Buckstein M, Stone NN and Stock R: Treatment outcomes and morbidity following definitive brachytherapy with or without external beam radiation for the treatment of localized prostate cancer: 20-year experience at mount sinai medical center. Urol Oncol 32: 38. e1-7, 2014.

17. Dickinson PD, Malik J, Mandall P, Swindell R, Bottomley D, Hoskin P, Logue JP and Wylie JP: Five-year outcomes after iodine-125 seed brachytherapy for low-risk prostate cancer at three cancer centres in the UK. BJU Int 113: 748-753, 2014.

18. Hayashi N, Izumi K, Sano F, Miyoshi Y, Uemura H, Kasuya T, Mukai A, Hata M and Inoue T: Ten-year outcomes of $I^{125}$ low-dose-rate brachytherapy for clinically localized prostate cancer: A single-institution experience in japan. World J Urol 33 $1519-1526,2015$.

19. McLaren DB, Kerr G, Law AB, Brush JP, Keanie J, Malik J, Keough W, Ronaldson T, Lee $\mathrm{J}$ and Kehoe T: The importance of prostate-specific antigen (PSA) nadir and early identification of PSA relapse after 10 years of prostate iodine 125 seed brachytherapy in edinburgh. Clin Oncol (R Coll Radiol) 27: 519-526, 2015.

20. Taira AV, Merrick GS, Butler WM, Galbreath RW, Lief J, Adamovich E and Wallner KE: Long-term outcome for clinically localized prostate cancer treated with permanent interstitial brachytherapy. Int J Radiat Oncol Biol Phys 79: 1336-1342, 2011.

21. Nanda A, Chen MH, Moran BJ, Braccioforte MH and D'Amico AV: Cardiovascular comorbidity and mortality in men with prostate cancer treated with brachytherapy-based radiation with or without hormonal therapy. Int J Radiat Oncol Biol Phys 85: e209-e215, 2013.
22. Margel D, Urbach DR, Lipscombe LL, Bell CM, Kulkarni G, Austin PC and Fleshner N: Metformin use and all-cause and prostate cancer-specific mortality among men with diabetes. J Clin Oncol 31: 3069-3075, 2013.

23. Taira AV, Merrick GS, Galbreath RW, Morris M, Butler WM and Adamovich E: Metformin is not associated with improved biochemical free survival or cause-specific survival in men with prostate cancer treated with permanent interstitial brachytherapy. J Contemp Brachytherapy 6: 254-261, 2014.

24. Shetti MB, Merrick GS, Butler WM, Galbreath R, Torlone A, Lief JH, Adamovich E and Wallner KE: The impact of diabetes mellitus on survival in men with clinically localized prostate cancer treated with permanent interstitial brachytherapy. Am J Clin Oncol 35: 572-579, 2012.

25. Wright JL, Plymate SR, Porter MP, Gore JL, Lin DW, Hu E and Zeliadt SB: Hyperglycemia and prostate cancer recurrence in men treated for localized prostate cancer. Prostate Cancer Prostatic Dis 16: 204-208, 2013.

26. Meng Y, Liao YB, Xu P, Wei WR and Wang J: Statin use and mortality of patients with prostate cancer: A meta-analysis. Onco Targets Ther 9: 1689-1696, 2016.

27. Kuban DA, Levy LB, Potters L, Beyer DC, Blasko JC, Moran BJ, Ciezki JP, Zietman AL, Zelefsky MJ, Pisansky TM, et al: Comparison of biochemical failure definitions for permanent prostate brachytherapy. Int J Radiat Oncol Biol Phys 65: 1487-1493, 2006 . 